\title{
Assessment of the Impacts of Tropical Cyclone Fantala to Tanzania Coastal Line: Case Study of Zanzibar
}

\author{
Kombo Hamad Kai, Mohammed Khamis Ngwali, Masoud Makame Faki \\ Tanzania Meteorological Authority (TMA), Zanzibar Office, Kisauni Zanzibar, Tanzania \\ Email:kombo.kai@meteo.go.tz,maso.1978@yahoo.com,mohamed.ngwali@meteo.go.tz
}

How to cite this paper: Kai, K.H., Ngwali, M.K. and Faki, M.M. (2021) Assessment of the Impacts of Tropical Cyclone Fantala to Tanzania Coastal Line: Case Study of Zanzibar. Atmospheric and Climate Sciences, 11, 245-266.

https://doi.org/10.4236/acs.2021.112015

Received: October 27, 2020

Accepted: February 23, 2021

Published: February 26, 2021

Copyright $\odot 2021$ by author(s) and Scientific Research Publishing Inc. This work is licensed under the Creative Commons Attribution International License (CC BY 4.0).

http://creativecommons.org/licenses/by/4.0/

\begin{abstract}
The study investigated the impacts of tropical cyclone (TC) Fantala $\left(11^{\text {th }}\right.$ to $27^{\text {th }}$ April, 2016) to the coastal areas of Tanzania, Zanzibar in particular. Daily reanalysis data consisting of wind speed, sea level pressure (SLP), sea surface temperatures (SSTs) anomaly, and relative humidity from the National Centres for Environmental Prediction/National Center for Atmospheric Research (NCEP/NCAR) were used to analyze the variation in strength of Fantala as it was approaching the Tanzania coastal line. In addition observed rainfall from Tanzania Meteorological Authority (TMA) at Zanzibar office, Global Forecasting System (GFS) rainfall estimates and satellite images were used to visualize the impacts of tropical cyclone Fantala to Zanzibar. The results revealed that, TC Fantala was associated with deepening/decreasing in SLP (from $1012-1010 \mathrm{mb}$ ) around the north-western Madagascar and coastal Tanzania, whereas the mean SSTs was greater than $28^{\circ} \mathrm{C}$ and an SSTs anomaly ranged from 0 to $2.3^{\circ} \mathrm{C}$. The vertical wind shear which ridged at Mozambican Channel and over north-eastern Madagascar was high enough (12 $15 \mathrm{~ms}^{-1}$ ) to support the intensifying of Fantala. The thermodynamic and dynamic conditions of Fantala influenced heavy rainfall of greater than $170 \mathrm{~mm}$ over most stations in Zanzibar. Moreover, Fantala disrupted the temporal variability of 2016 March to May (MAM) seasonal rainfall. Besides, more than 420 people were homeless, at least 3330 houses were destroyed, and about 2 people died. As for mainland Tanzania Fantala resulted in a death of 12 people in Kilimanjaro and Arusha, more than 315 houses were washed away by flooding leading to 13,933 people being homeless. Conclusively the study calls for an extensive research work based on examining and forecasting the TCs rainfall impacts and their contribution during the two rainfall seasons of OND and MAM in Tanzania.
\end{abstract}




\section{Keywords}

Tropical Cyclone, Fantala, Sea Surface Temperatures (SSTs), Dynamics and Thermodynamics, Forecasting Systems, and MAM Seasonal Rainfall, Vorticity, Wind Shear, Vertical Profile

\section{Introduction}

Tropical cyclones (TCs) are among the most devastating natural atmospheric phenomenon which results in damages to property, infrastructure, marine species and even the loss of lives [1] [2] [3]. The Southwestern Indian Ocean (SWIO) basin is among the tropical basins most prone to TCs [4]. These areas have strongest TCs in January and highest frequency of TCs from December to March (DJFM) [5] [6].

In the Western Indian Ocean (WIO), the TCs often lead to catastrophic environmental and socio-economic impacts [7] [8]. For instance, over Mozambique, TC Eline in 2002 TC season, was associated with enhanced flooding with the estimated death toll of up to 700 people, and the livelihoods of about 2 million people were affected [9]. As for the East African (EA) coastal waters, historical records show that, it is not often for the TCs to pass near EA coastal waters [10], and the only cyclones are that occurred at Lindi in 1958 [11] and the other ones occurred in Zanzibar and Bagamoyo since 1872, whereas the last was that occurred in Zanzibar in 1994 [12]. These tropical cyclones had just approached the EA coastal waters, and brought significant impacts to the coast of Tanzania, with devastating impacts in Zanzibar.

The tropical cyclone Fantala on its tropical depression (TD) stage was forecasted to pass EA water and probably hit the Tanzania coastline. However, it turned (recurred) back to the northeastern tip of Madagascar and re-intensified to be severe tropical cyclone Fantala. On $17^{\text {th }}$ to $18^{\text {th }}$ April, 2016, Fantala was intensified to be a category 4 tropical cyclone and hence resulted in heavy rainfall, strong winds and waves with devastating impacts to Zanzibar. Since TCs and TSs season over the SWIO is coincided with the rainfall seasons of October to December (OND) and March to May (MAM) of the EA and Tanzania in particular [6]. Indeed, TCs are among the predictors used by IGAD Climate Prediction and Analysis Center (ICPAC) to foresee the likelihood of the OND and MAM seasonal rainfall over the IGAD region. Thus, the strength of TCs is of crucial issues of concern to socio-economic livelihoods of people over this area. Hence analysing the strength, socio-economic and livelihoods impact of Fantala on Tanzania and Zanzibar is of great importance. Currently the impacts of Fantala to EA and Zanzibar in particular are either not yet known or not well documented. Thus, this study aimed to examine the dynamics of Fantala and investigate the strength and magnitude of its impacts on Zanzibar. 


\section{Objectives}

The purpose of this study was to analyze the extent to which the devastating nature of the tropical cyclone Fantala affects the socio-economic and livelihoods aspects in Zanzibar. Moreover, among other things the study aimed at understanding the extent to which the Fantala disrupted the 2016 March to May (MAM) seasonal rainfall in Tanzania and Zanzibar in particular.

\section{Data and Methods}

The study used the daily reanalysis data of wind speed, sea level pressure (SLP), sea surface temperatures (SSTs) anomaly, and relative humidity from the National Centres for Environmental Prediction/National Centre for Atmospheric Research (NCEP/NCAR). Wind speed data with spatial resolution $2.5^{\circ} \times 2.5^{\circ}$ were used to derive the large scale environmental parameters namely, vertical wind shear between $200-850 \mathrm{mb}$ (hereafter $\mathrm{VWS}_{28}$ ) and low level relative vorticity $\left(\operatorname{LLVR}_{85}\right)$. The thermodynamic parameters including daily Sea Surface Temperature (SSTs) anomaly of spatial resolution $2.0^{\circ} \times 2.0^{\circ}$ (Reynolds et al. 2007) [13] and daily relative humidity data at 850 and $700 \mathrm{mb}$ with spatial resolution of $2.5^{\circ} \times 2.5^{\circ}$ were used to observe the variation of heat content during the life of Fantala. The seasonal MAM, 2016 rainfall records and the daily rainfall records during the occurrence of TC Fantala were acquired from TMA Zanzibar office (i.e. Zanzibar observations stations). Also the convection channel satellite images showing the storm impacts and position of Fantala on specific date and time were acquired. The forecasted rainfall maps for the $16^{\text {th }}$ and $17^{\text {th }}$ April, 2016 during the occurrence of Fantala were downloaded from the OGIMET GFS models cited by (https://www.ogimet.com/show_foremaps.php). Indeed, the model forecast was validated by the observation from various stations in Zanzibar. Besides, datasets from the second vice presidents office of the Revolutionary Government of Zanzibar $\left(\mathrm{R}_{\mathrm{O}} \mathrm{GZ}\right)$ in the commission for disaster management were used to quantify impacts of Fantala.

Variability of daily mean SSTs anomalies along the geographical region defined by $39^{\circ} \mathrm{E}$ to $100^{\circ} \mathrm{E}$ and $40^{\circ} \mathrm{S}$ to $5^{\circ} \mathrm{N}$ during $15^{\text {th }}$ to $20^{\text {th }}$ April, 2016 was also plotted and analyzed to feature the variation of the SSTs anomalies during Fantala. Moreover, the 10 days average SSTs anomalies before, during, and after Fantala was also plotted to feature the SSTs conditions (differences) during these three periods. The daily mean wind vectors at 850 and $200 \mathrm{mb}$ for $15^{\text {th }}$ to $20^{\text {th }}$ April 2016 were plotted and analyzed. Like in SSTs analysis, the 10 days mean wind vectors at $850 \mathrm{mb}$ before, after, and during Fantala was also plotted and analyzed. Similar analytical algorithm was undertaken for relative humidity $(\mathrm{Rh})$ at 850 and $700 \mathrm{mb}$ and sea level pressure (SLP) for both daily, and 10 days average before, during, and after Fantala. Moreover, vertical variation of Rh for different days of the cyclone Fantala and its vertical profile during $17^{\text {th }}$ April, 2016 at $12^{\circ} \mathrm{S}, 52^{\circ} \mathrm{E}$ (hereafter A) and $2.5^{\circ} \mathrm{S}, 42.5^{\circ} \mathrm{E}$ (hereafter B) were also plotted. The vertical wind shear $(200-850 \mathrm{mb})$ which has inverse relationship with TCs de- 
velopment and intensity and a time lag of about 36 hours [14], and which affects the genesis and intensification of TCs [15] [16] [17] was derived using the [18] and [3] relation which defines the wind shear as the difference in horizontal wind from 200 to $850 \mathrm{mb}$ as given by the relation

$$
V W S_{28}=\sqrt{\left(\left(U_{200}-U_{850}\right)^{2}+\left(V_{200}-V_{850}\right)^{2}\right)}
$$

where, $U_{200}, U_{850}$ and $V_{200}, V_{850}$ are the zonal and meridional wind fields at 200 and $850 \mathrm{mb}$, respectively.

The geographic region of $39^{\circ} \mathrm{E}-100^{\circ} \mathrm{E}$ and $40^{\circ} \mathrm{S}-5^{\circ} \mathrm{N}$ was used to display the daily variation of the derived $\mathrm{VWS}_{28}$ for the 10 days average before, during and after Fantala. This was done to see the dates and areas of which Fantala was being intensified or diminished based on the fact that, TCs strength is inversely related to $\mathrm{VWS}_{28}$ [13]. Apart from the $\mathrm{VWS}_{28}$ strength, the westerly $\left(-\mathrm{VWS}_{28}\right)$ and easterly $\left(+\mathrm{VWS}_{28}\right)$ flow variation of the $\mathrm{VWS}_{28}$ was also observed and analyzed. Moreover, the vertical profiles of zonal (v) and meridional (v) winds at points A and $B$ during the Fantala days $\left(13^{\text {th }}\right.$ to $27^{\text {th }}$ April, 2016) from surface to $100 \mathrm{mb}$ was plotted to observe the variation of these winds with height for each Fantala day. The low level vorticity $\left(\operatorname{LLVR}_{85}\right)$ at $850 \mathrm{mb}$ was also derived using the finite difference scheme [19] and the $\mathrm{LLVR}_{85}$ maps were displayed and analyzed to feature the influence of the cyclone as it approaches the land. Besides, the vorticity vertical profiles (surface to $100 \mathrm{mb}$ ) at points A and B were plotted to feature the variations of the vortex with height during Fantala.

Lastly the variability of the MAM seasonal rainfall for four consecutive seasons of 2013, 2014, 2015 and 2016 were investigated relative to the 2016 MAM rainfall season. Also the rainfall performance of 17 days of TC Fantala was analyzed in relation to April and MAM, 2016 rainfalls. In this analysis the seasonal and monthly percentage contribution of the Fantala associated rainfall was calculated. The OGIMET GFS model forecasts images, the real time satellite images for the rainfall approximations during the Fantala days were also analyzed. The impacts of the Fantala from various socio-economical areas were analyzed using the photographs taken during the event, and the floods victims' data collected by the department of disaster management in the second vice presidents office. Lastly the cost incurred during Fantala was also estimated.

\section{Results and Discussion}

\subsection{Dynamic and Thermodynamics of Tropical Cyclone Fantala}

The results of the analysis of the dynamics and impacts of Fantala to coastal Tanzania Zanzibar in particular show that, the 10 days average SSTs anomaly before Fantala (Figure 1(a)) had higher SSTs anomalies ranged from $0-2^{\circ} \mathrm{C}$, over the SWIO region, but the 16 days average SST anomaly during Fantala (Figure 1(b)) showed that, the highest SST anomaly which ranged from 0 $2.5^{\circ} \mathrm{C}$ over the SWIO was located at the region defined by $0^{\circ}-5^{\circ} \mathrm{S}$ and $50^{\circ} \mathrm{E}-$ $55^{\circ} \mathrm{E}$. These results indicate that during Fantala most SWIO areas were asso- 
ciated with higher SSTs anomaly, and it should be noted that, higher SSTs anomalies play a vital role in cyclone genesis and intensification as supported by [5] [9] among others. Moreover, the study results of higher SSTs anomalies during Fantala is well agreed by [20] who noted that, higher SSTs acts as a critical parameter necessary to fuel intensification of thunderstorms that may grow into a cyclone. Besides, the results in Figure 1(b) showed the lowest SST anomaly ranged from $0-1^{\circ} \mathrm{C}$ at northern tip of Madagascar. This lowest SSTs anomaly could be explained by upwelling of sea water caused by the spinning of the cyclone at the ocean surface. As for the daily mean variation of SSTs during Fantala (figures were not shown) the results revealed a great increase in daily mean SSTs with a range of $28^{\circ} \mathrm{C}-32^{\circ} \mathrm{C}$ northward of $20^{\circ} \mathrm{S}$, indicating that the area tracked by Fantala had highest SSTs levels (ocean warmth) resulting to higher evaporation potentials as supported by [21] who noted that the warmer SSTs favoring deep convection. Also [22] noted that SST in the source regions is strongly correlated with precipitation in the rainy season, and that oceanic area is defined as a significant source of precipitation when on average more than $20 \%$ of the total evaporation, and at least $250 \mathrm{~mm} / \mathrm{yr}$ of evaporation ends up as continental precipitation. Thus, our finding and that of [21] and [22] indicate that evaporation from the oceans is the primary source of water vapor in the atmosphere i.e. the warmer the water, the greater the evaporation. Furthermore, the results of the 10 days SSTs anomalies after Fantala (Figure 1(c)) show that, though the Fantala had passed, but the SSTs strengths were still high over the SWIO region. This result may indicate that the existence and decay of cyclone is influenced by more factors apart from SSTs.

The results of the analysis of the distribution of relative humidity during Fantala life revealed highest moisture distribution at $850 \mathrm{mb}$ level (Figure 2(a)) mapped over the entire coastal and hinterland areas of Tanzania as well at north eastern Madagascar where the cyclone eye was positioned, this moisture content
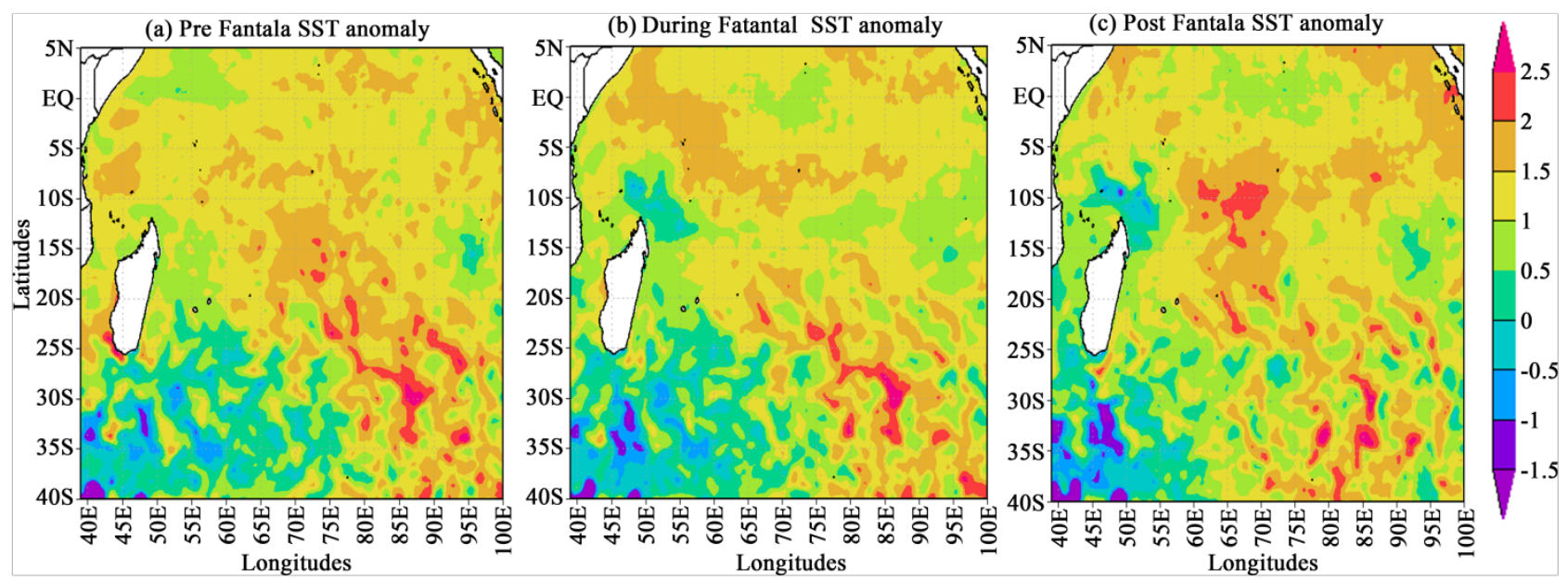

Figure 1. The distribution of the average SST anomalies for 10 days average before Fantala (a) 16 days average during Fantala (b) and 10 days average after Fantala (c). It should be noted that the analysis during Fantala was for 16 days based on its life span (13 ${ }^{\text {th }}$ to $27^{\text {th }}$ April 2016). 

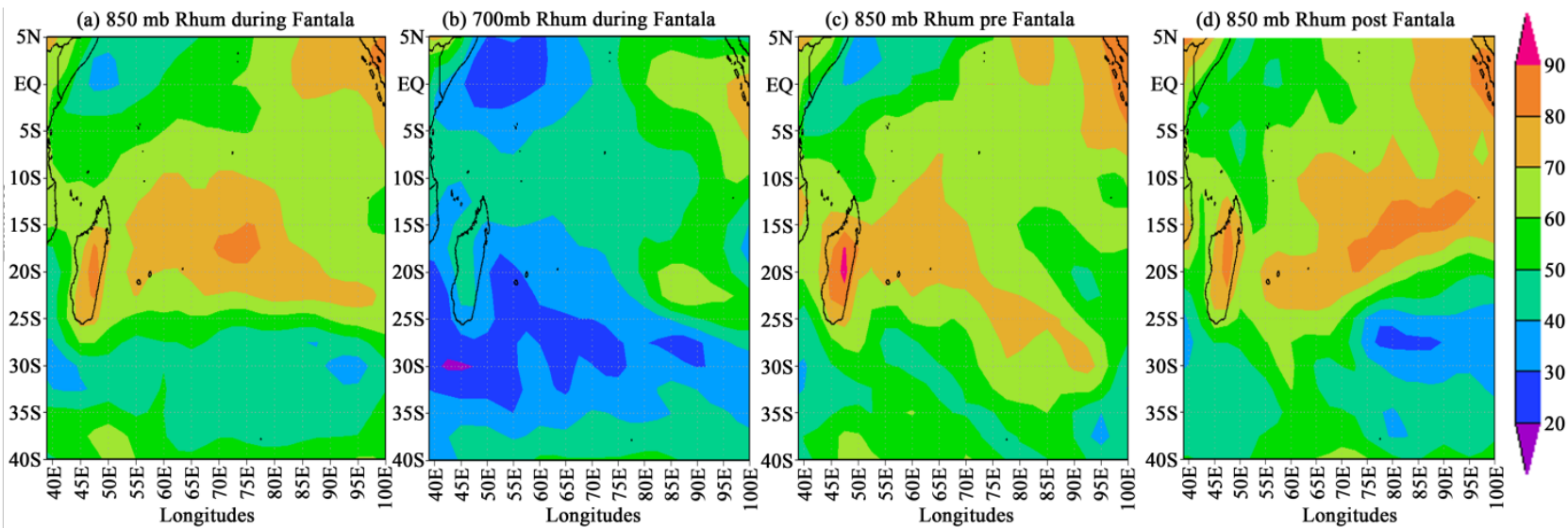

Figure 2. The distribution of (a) $850 \mathrm{mb}$ and (b) $700 \mathrm{mb} \mathrm{Rh}$ during the Fantala; where (c) and (d) shows the ten 10 days average moisture distribution before, and after Fantala, respectively.
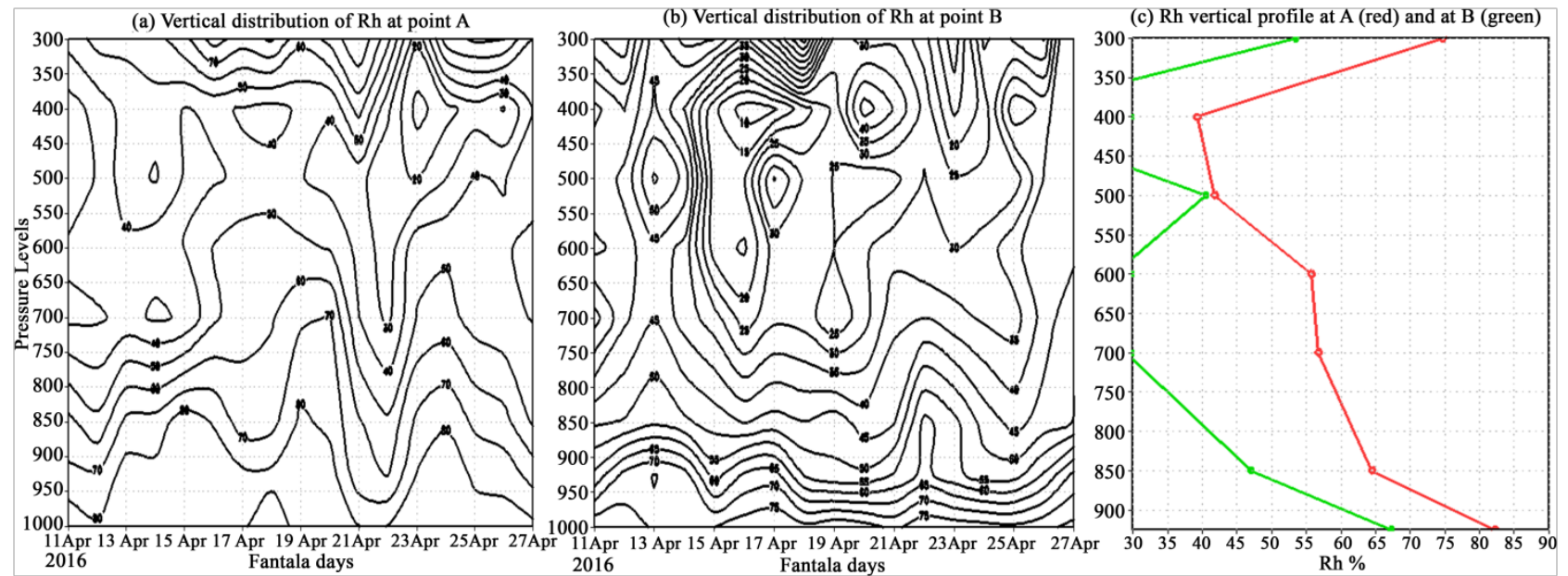

Figure 3. The vertical profile of Rh during Fantala: (a) vertical distribution of Rh at point A (b) same as (a) but for point B and (c) the vertical profile of $\mathrm{Rh}$ on $17^{\text {th }}$ April, 2016, at point A and B (red and green curves). 
height. The results in Figure 3(a) was mimicked by that of Figure 3(b), where at low levels (surface to $700 \mathrm{mb}$ ) moisture column was increasing with height, and limited moisture content was seen at the middle of the atmosphere (i.e. 700 - 450 $\mathrm{mb}$ ), whereas at the top of the atmosphere the moisture was increase with height. As for the vertical moisture distribution on $17^{\text {th }}$ April, 2016 at points $\mathrm{A}$ (red curve) and B (green curve) Figure 3(c), revealed that at both points the moisture was decreasing with height from 925 to $850 \mathrm{mb}$ with A having higher $\mathrm{Rh}$ relative to B. Moreover, results in Figure 3(c) show that, at 850 to $700 \mathrm{mb}$ the Rh was slightly increasing with height with further increase from 700 to 600 $\mathrm{mb}$, above this level the $\mathrm{Rh}$ for point $\mathrm{A}$ was further increased with height from $400 \mathrm{mb}$ onwards, but that of B had constantly lower Rh. The higher moisture distribution at lower level and low moisture at mid level followed by higher moisture at upper level (Figure 3) indicate the rising motion at the lower levels followed by sinking motion middle levels, and this midlevel drier conditions tends to retard the formation of intense convection which results in TCs [23] associated with the radiative cooling [24]. This moisture variation with both time and height can also explain the variation of strength of Fantala with time as well as the variation of the rainfall impacts as you approaches the coastal areas.

The results of the mean sea level pressure (slp) 10 days before, during and after Fantala Figures 4(a)-(c) revealed that, 10 days before the cyclone (Figure 4(a)) the coastal areas and the entire Tanzania was under the influence $1012 \mathrm{mb}$ ridge, but during the cyclone a significant fall pressure was notice. For instance, both the northern tip of Madagascar and coastal Tanzanian and her hinterlands was under the influence of the low pressure trough of $1010 \mathrm{mb}$ Figure 4(b) \& Figure $4(\mathrm{c})$. This low pressure trough allow the surface to midlevel/upper level convergence/divergence of air which results in rising (low level)/sinking (upper level) motion [24]. Moreover, the results of low pressure during the TCs presented in Figure 4(b) \& Figure 4(c) are supported by [25] [26] that, TCs pressure relationship had predictive utility i.e. the TCs strength are inversely related to pressures strengths. Furthermore, the 10 days average SLP after the storm show that, the ridge which was existed before the cyclone has recovered and hence affect the weather over most parts of the coastal line. This affecting of weather condition was influence by surface divergence associated with upper level confluence.

The results of the distribution of average wind circulation at $850 \mathrm{mb}$ for 10 days before, 16 days during and 10 days after Fantala, presented in (Figure 5) shows that the wind circulation for 10 days average before Fantala (Figure 5(a)) was slight along the coastal areas of Tanzania, and was showing weak circulation at north eastern side of Madagascar, but with strong speed at the northern tip of Madagascar. Likewise, weak cyclonic circulation was observed at north eastern side of Madagascar (at about $8^{\circ} \mathrm{S}-17^{\circ} \mathrm{S}$ and $55^{\circ} \mathrm{E}-75^{\circ} \mathrm{E}$ ) indicating the development of low level depression/storm around that area. Over coastal Tanzania and hinterlands Figure 5(a) reveals a low level winds were more easterly, but with increasing speed.

The results in Figure 5(a) revealed a weak wind circulation at the north eastern 
(a) SLP on pre Fantala

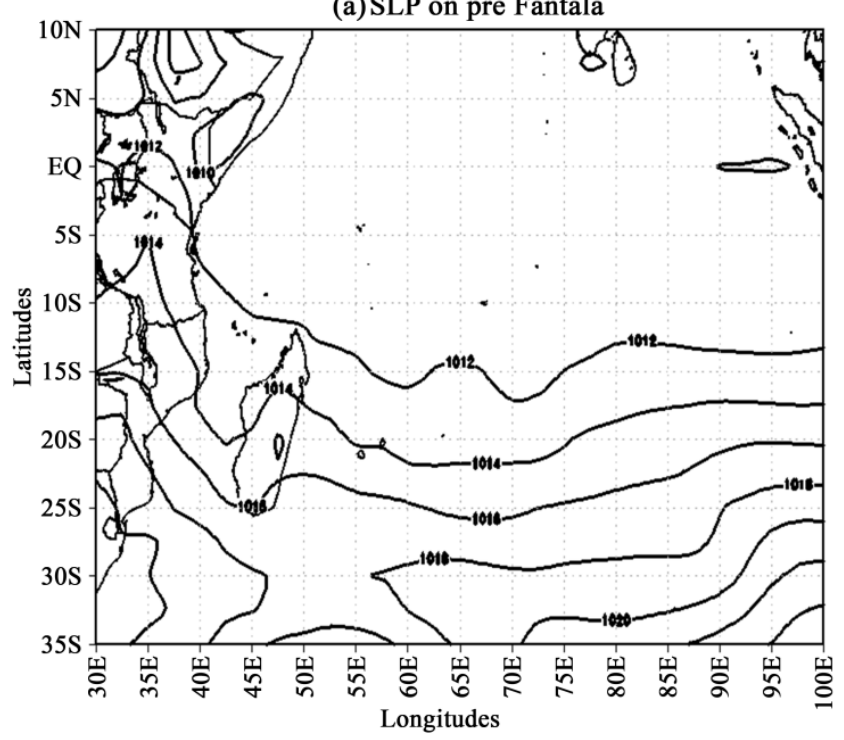

(b) SLP on $18^{\text {th }}$ April, 2016 during Fantala

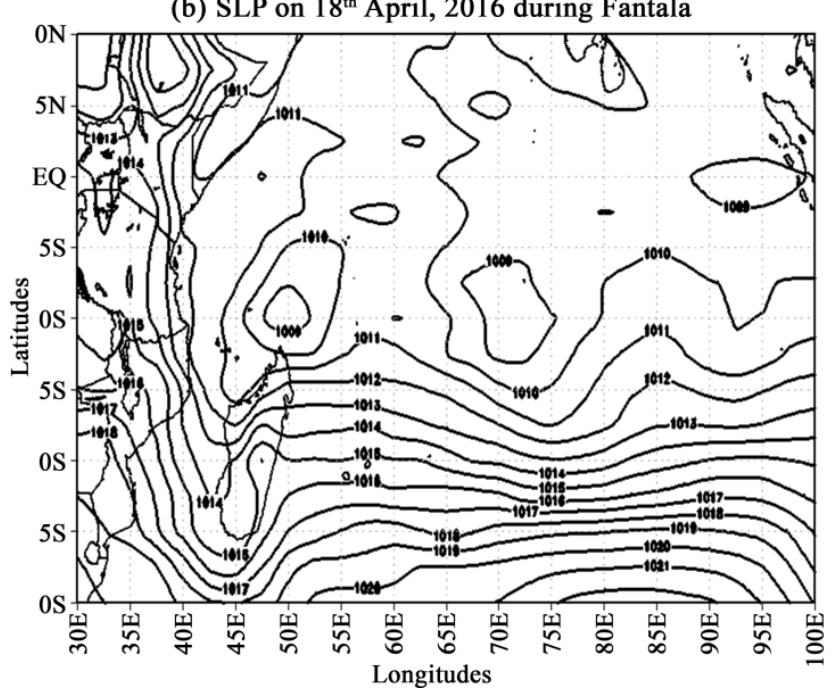

(b) SLP on $17^{\text {th }}$ April, 2016 during Fantala

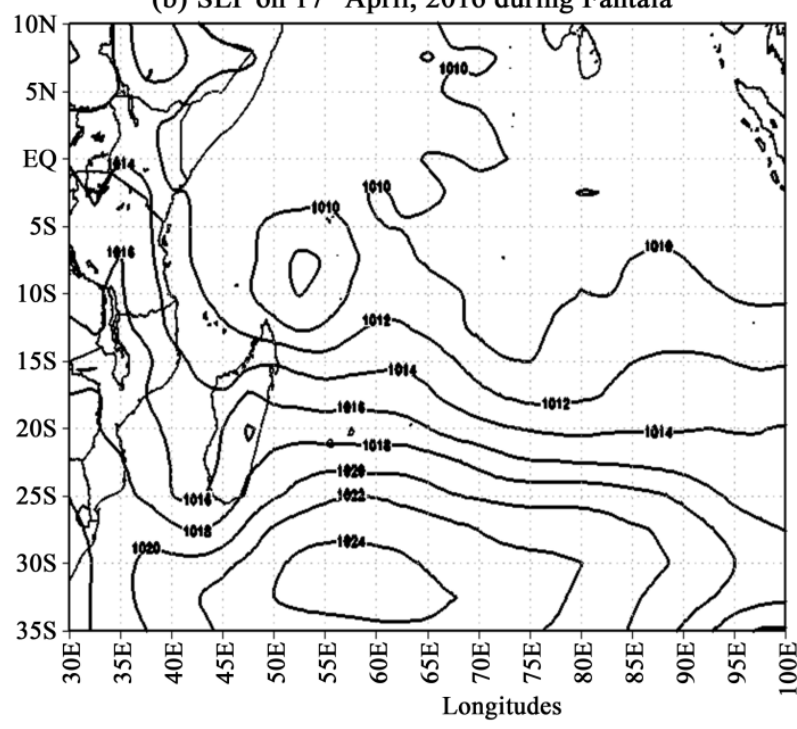

(d) SLP on post Fantala

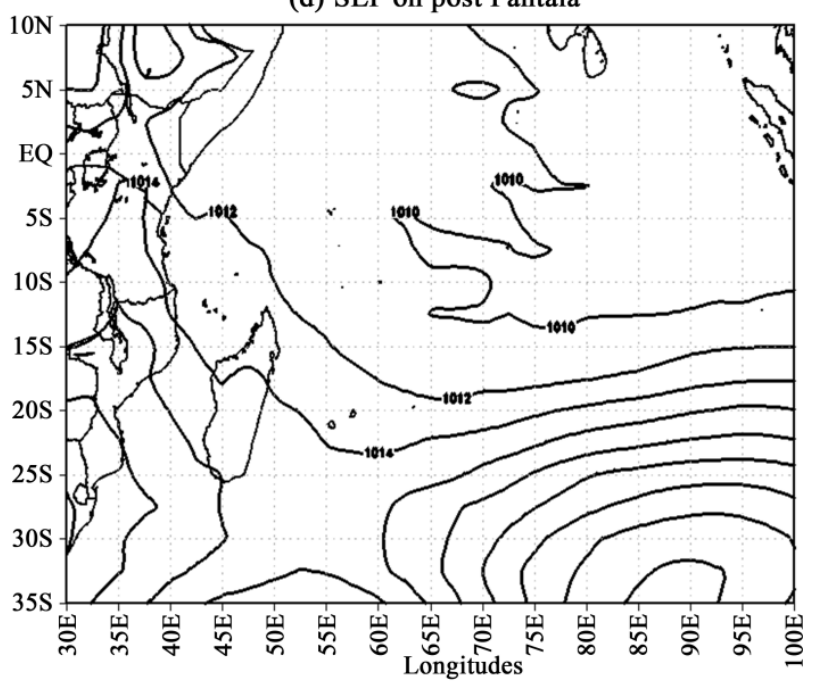

Figure 4. The distribution of the mean SLP at the SWIO; where (a) shows the 10 days average SLP before the cyclone; (b) and (c) are the $17^{\text {th }}$ and $18^{\text {th }}$ April, 2016 SLP distribution during the Fantala, and (d) shows the 10 days average SLP after the Fantala.

tip of Madagascar $\left(45^{\circ} \mathrm{E}-73^{\circ} \mathrm{E}\right.$ and $\left.5^{\circ} \mathrm{S}-12^{\circ} \mathrm{S}\right)$, indicating that the weak circulation was shifted further west near the coast of Tanzania. Results in Figure 5(b) show that, the coastal and hinterland areas were characterized by long track strong south easterlies indicating low level moisture content was pushed to these areas. The wind circulation on $17^{\text {th }}$ April, 2016 (the day which resulted in heavy downfall and flooding over Zanzibar and coastal Tanzania at large) the results presented in Figure 5(c) show that, on this day the cyclonic circulation was at the tip of Madagascar with slight south easterly winds linearly covering the entire coastal belt of Tanzania, indicating the high moisture deposition which triggered the flooding events. The results in Figure 5(d) revealed that, the low level wind circulation along Tanzania has been dominated by the influence of high pressure ridge situated southern Mozambique leading the coastal Tanzania with 
(a) $850 \mathrm{mb}$ average wind circulation pre Fantala

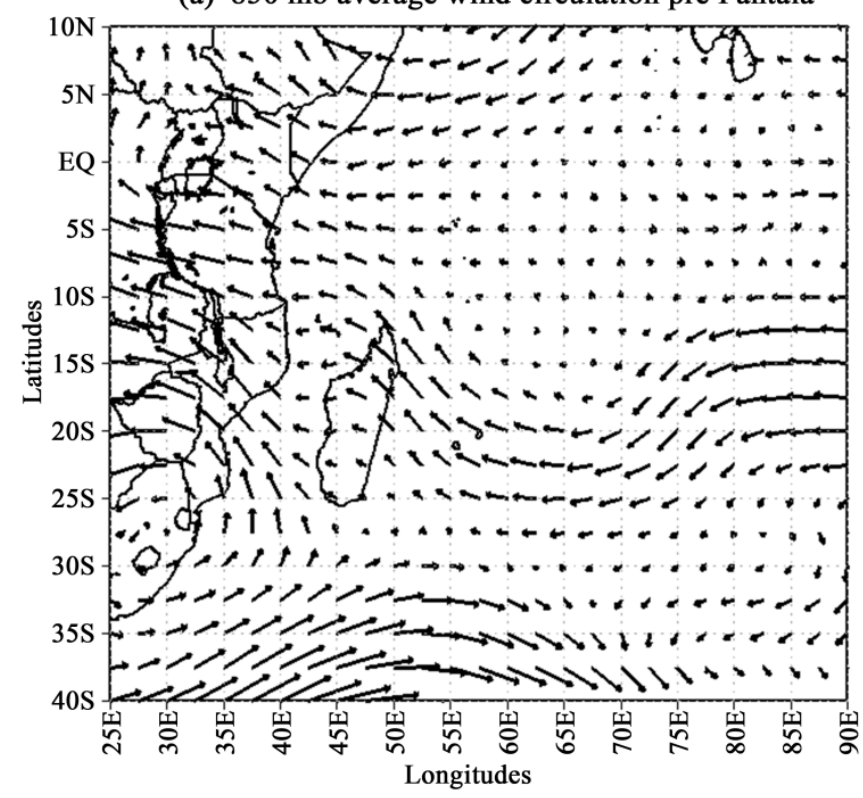

(c) $850 \mathrm{mb}$ average wind circulation on $17^{\text {th }}$ April, 2016

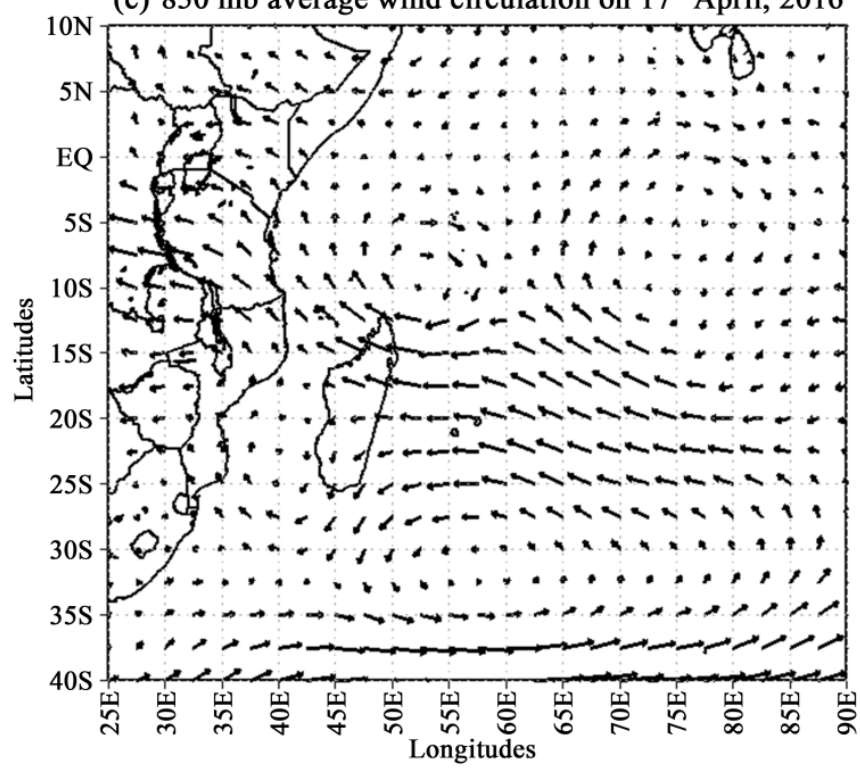

(b) $850 \mathrm{mb}$ average wind circulation during Fantala

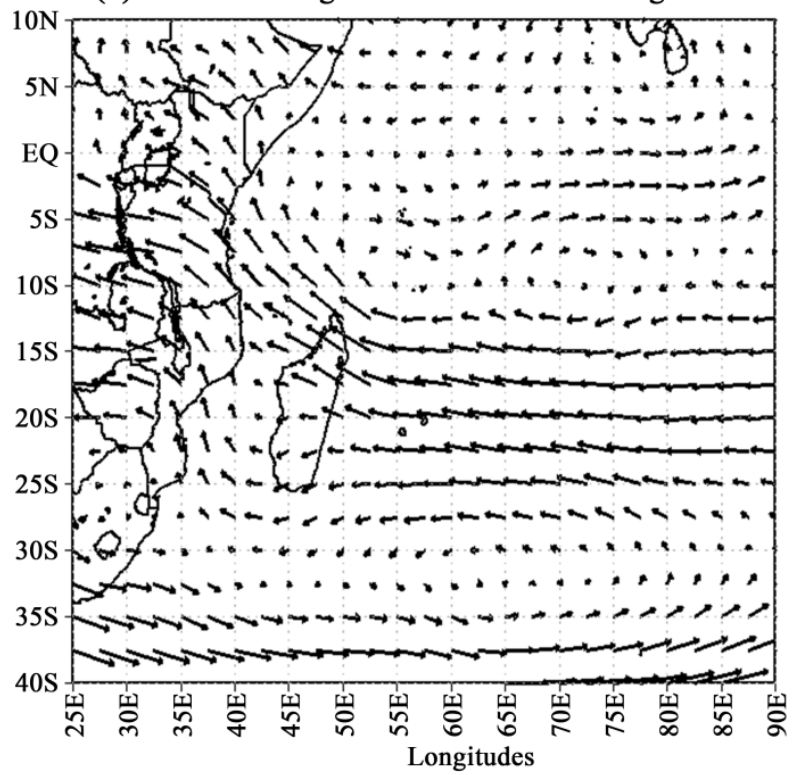

(d) $850 \mathrm{mb}$ average wind circulation post Fantala

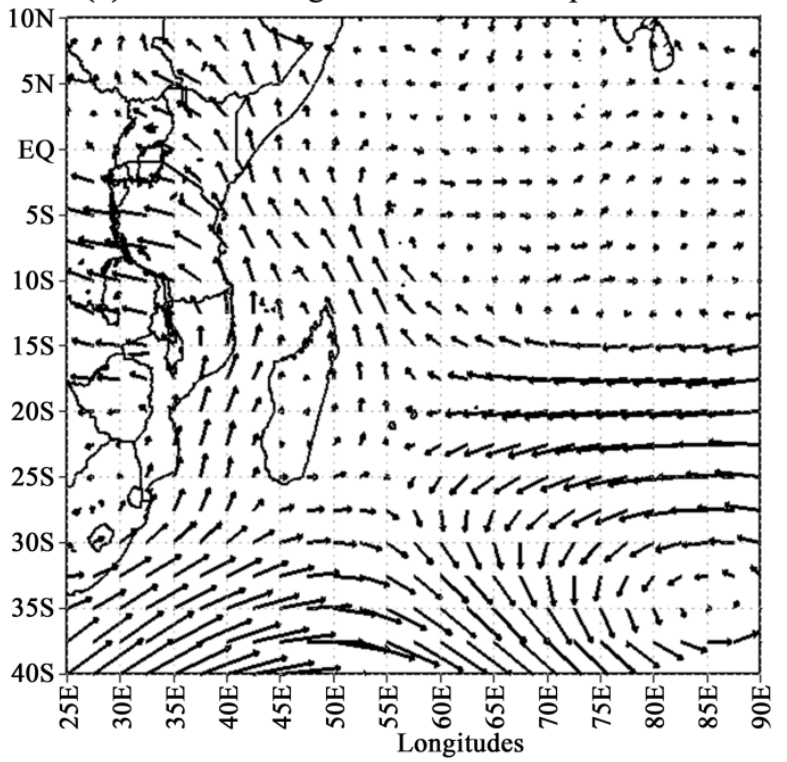

Figure 5. The average low level $(850 \mathrm{mb})$ wind circulation, over the SWIO region; where (a) ten days average before Fantala, (b) sixteen days average during Fantala and (c) shows wind strength on $17^{\text {th }}$ April 2016, and (d) the ten days wind circulation after Fantala.

strong anti-cyclonic south easterlies which further decline the weather along the coastal Tanzania and its hinterlands.

The tracks of Fantala were forecasted to reach the coastal Tanzania, but when it reached near the East African (EA) coastal waters (EA coastal current) it recurred (turned) back to its original track. The results of the analysis of the $\mathrm{VWS}_{28}$ during $20^{\text {th }}$ to $27^{\text {th }}$ April, 2016 presented in Figure 6 explain why the Fantala recurred back. Figure 6 shows that, the $5 \mathrm{~ms}^{-1} \mathrm{VWS}_{28}$ contour on $23^{\text {rd }}$ April, 2016 was ridged at the tip of Madagascar (Figure 6(a)), whereas on $25^{\text {th }}$ April 2016 (Figure 6(b)), the strength of $\mathrm{VWS}_{28}$ at the same place was at 10 
(a) $\mathrm{VWS}_{28}$ on $23^{\text {rd }}$ April, 2016

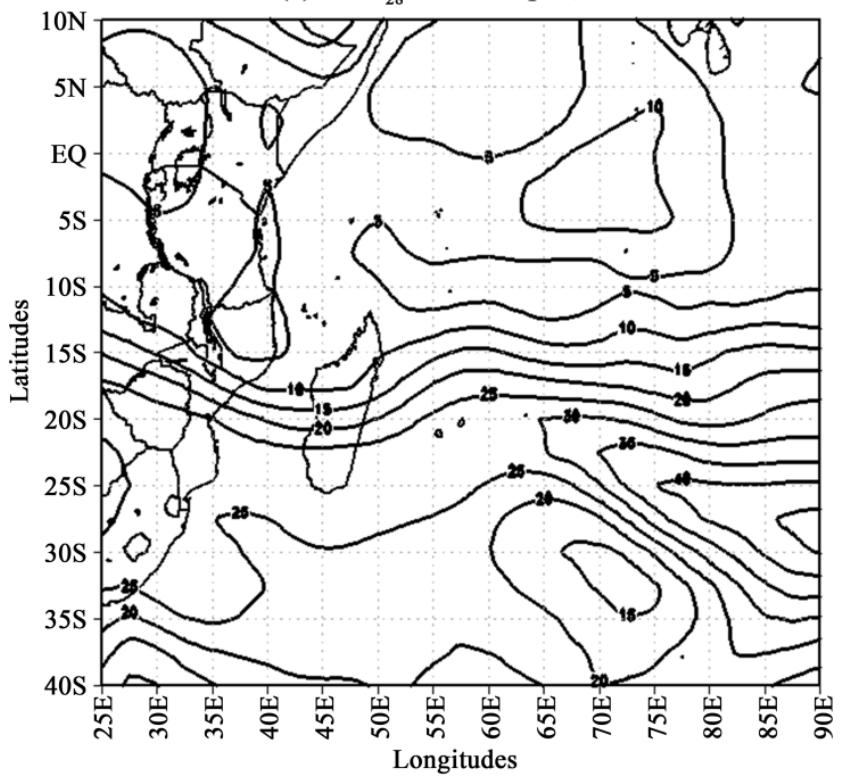

(c) $\mathrm{VWS}_{28}$ on $26^{\text {th }}$ April, 2016

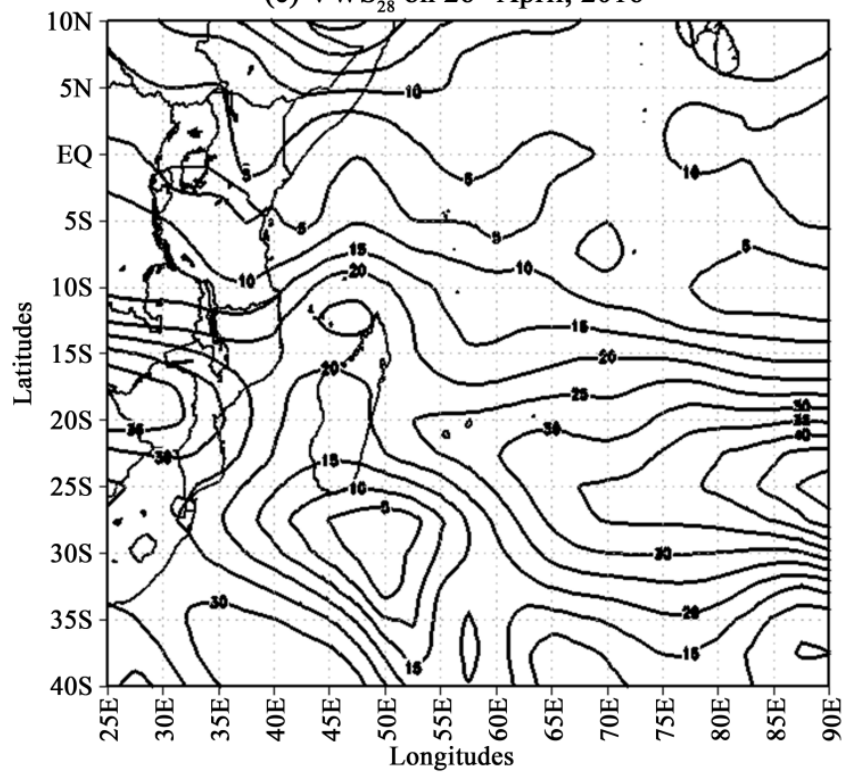

(b) $\mathrm{VWS}_{28}$ on $25^{\text {th }}$ April, 2016

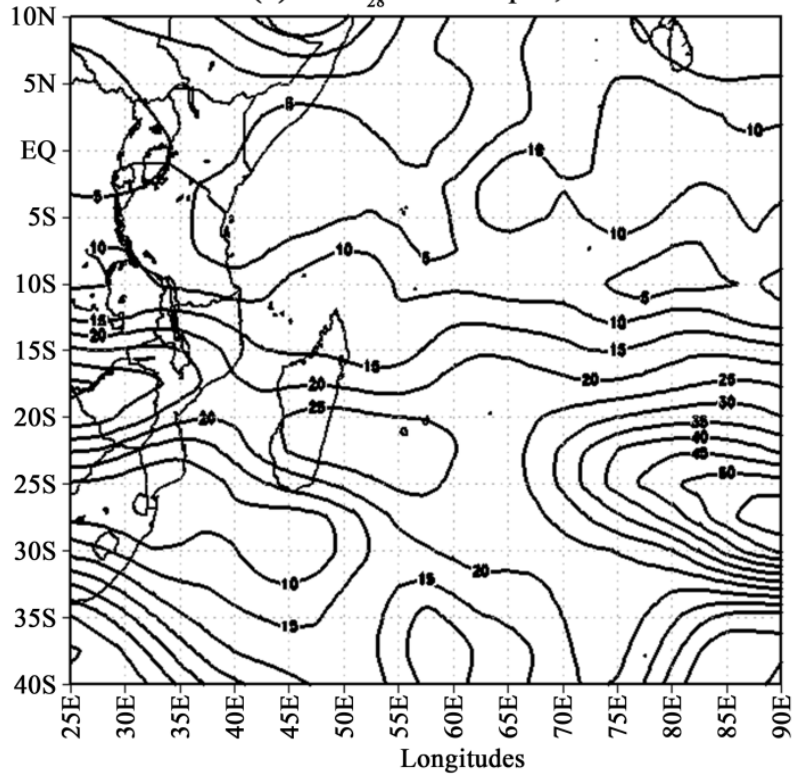

(d) Average $\mathrm{VWS}_{28}$ on $20^{\text {th }}$ to $27^{\text {th }}$ April, 2016

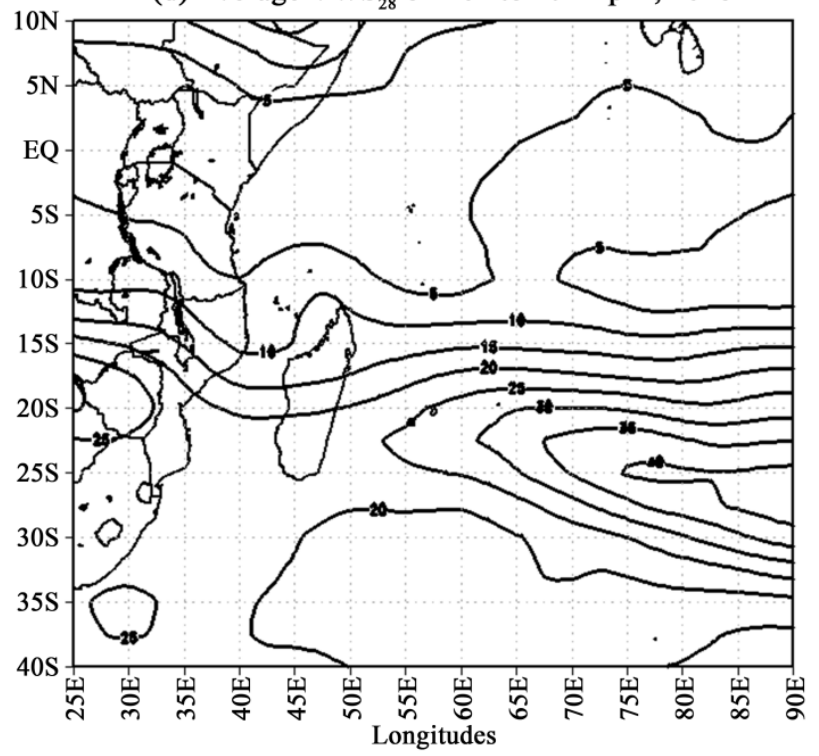

Figure 6. The distribution $\mathrm{VWS}_{28}$ along the SWIO during Fantala; where (a), (b) and (c) are distribution $\mathrm{VWS}_{28}$ for $23^{\text {rd }}, 25^{\text {th }}$ and $26^{\text {th }}$ April 2016, and (d) shows the 8 days $\left(20^{\text {th }}-27^{\text {th }}\right.$ April, 2016) average $\mathrm{VWS}_{28}$ distribution.

$\mathrm{ms}^{-1}$, and on $26^{\text {th }}$ April, 2016 (Figure 6(c)) the strength of $\mathrm{VWS}_{28}$ at the tip was further increased to be $15 \mathrm{~ms}^{-1}$, the level in which the strength of the cyclone is much affected. The presented results in Figure 6 are in agreement with number of studies of including [27] [28] [29] [30], and [18], whom they conclude that the average $\mathrm{VWS}_{28}$ threshold which supports TCs development, intensification and dissipation to decaying varies between 10 and $15 \mathrm{~ms}^{-1}$ (depending on the basin) while references [27]; [28] and [30] had gone further and stated that, $\mathrm{VWS}_{28}$ of less than $10 \mathrm{~ms}^{-1}$ favors rapid intensification and that greater than 10 $\mathrm{ms}^{-1}$ favors decay, thus the results in Figure 6 show that as days go on, the 
strength of $\mathrm{VWS}_{28}$ at the tip and at the Mozambican channel was increasing. Furthermore, the results in Figure 6(d) revealed that, the $10 \mathrm{~ms}^{-1} \mathrm{VWS}_{28}$ contour of the 8 days average was also ridged at the tip of Madagascar meaning that from $22^{\text {nd }}$ April, 2016 the $\mathrm{VWS}_{28}$ at the northern, western and even at the Mozambican channel was in the state to deny further intensification of Fantala. Moreover, Figure 6(d) revealed that, from $20^{\text {th }}$ to $27^{\text {th }}$ April, 2016 the conducive conditions for development and intensification of Fantala was progressing further north towards the equator, the area to which the second criterion for TCs formation (i.e. at least $5^{\circ}$ latitude far from equator) was not met. Besides, the results shows that at the northern tip of Madagascar the $10 \mathrm{~ms}^{-1} \mathrm{VWS}_{28}$ was ridged from deep South-eastern Indian Ocean (SEIO), and the low $\mathrm{VWS}_{28}$ contours for TC intensification $\left(5-6 \mathrm{~ms}^{-1}\right)$ was shifted further westward at the geographical region defined by $60^{\circ} \mathrm{E}-90^{\circ} \mathrm{E}$ and $0^{\circ}-7^{\circ} \mathrm{S}$.

The results of the vertical vorticity profile at points $A$ and $B$, and the vertical distribution (surface to $100 \mathrm{mb}$ ) of zonal (u) and meridional $(\mathrm{v})$ winds from $13^{\text {th }}$ to $27^{\text {th }}$ April, 2016 during Fantala presented in Figure 7 revealed that, the vorticity at point A (Figure 7(a)) was highly negative (of the order $-10^{-6} \mathrm{~S}^{-1}$ ) from surface to $150 \mathrm{mb}$ during $13^{\text {th }}$ to $21^{\text {st }}$ April 2016, and during $21^{\text {st }}$ to $23^{\text {rd }}$ the vorticity became 0 from surface to $200 \mathrm{mb}$ indicating declined weather condition during $21^{\text {st }}$ to $23^{\text {rd }}$ April, whereas during $23^{\text {rd }}$ to $25^{\text {th }}$ the vorticity became negative again with the same order of magnitude, and during $27^{\text {th }}$ April onwards, the vorticity became positive at all levels. As for vorticity vertical profile at point $\mathrm{B}$ during $15^{\text {th }}$ to $27^{\text {th }}$ April, 2016 (Figure $7(\mathrm{~b})$ ) the results revealed that, though the vorticity (surface to $500 \mathrm{mb}$ ) was positive on $15^{\text {th }}$ to $24^{\text {th }}$ but was very weak. Whereas during $26^{\text {th }}$ to $27^{\text {th }}$ the vorticity tended to capture high negative numbers from surface to $200 \mathrm{mb}$ indicating the high negative tilt. This tilt affected the vertical air motion for cloud formation and precipitation, but in general the cloud formation and precipitation was highly supported by the low negative vorticity at the surface to $700 \mathrm{mb}$ as compared to that at the upper air. Moreover, the results Figure 7(a) \& Figure 7(b) indicate that, point A had strong weather activities than $\mathrm{B}$. The results of the zonal wind variation with both time and height at point B (near the Tanzanian coast) presented in Figure 7 (c) revealed that from $13^{\text {th }}$ to $24^{\text {th }}$ April the atmosphere was governed by westerly winds flow from surface to $300 \mathrm{mb}$ which its strength was increasing with height especially from $13^{\text {th }}$ to $17^{\text {th }}$ April, 2016. This westerly flow indicates that moist air was sucked from the Congo airmass to fill the low pressure patterns at the centre of the cyclonic circulation at the northern eastern Madagascar. Besides, the results revealed that on $24^{\text {th }}$ to $27^{\text {th }}$ the zonal wind flow at point B changes to be easterly, and hence affecting the energy generation of the cyclone due to lack of enough moisture leading to decay of Fantala.

Normally TCs are more responsible for ocean mixing and heat stratification, where surface or skin temperatures cools and subsurface to deep oceanic levels warms, and this warmed water may be transferred poleward using the meridonal 
(a) vertical distribution of vorticity at A

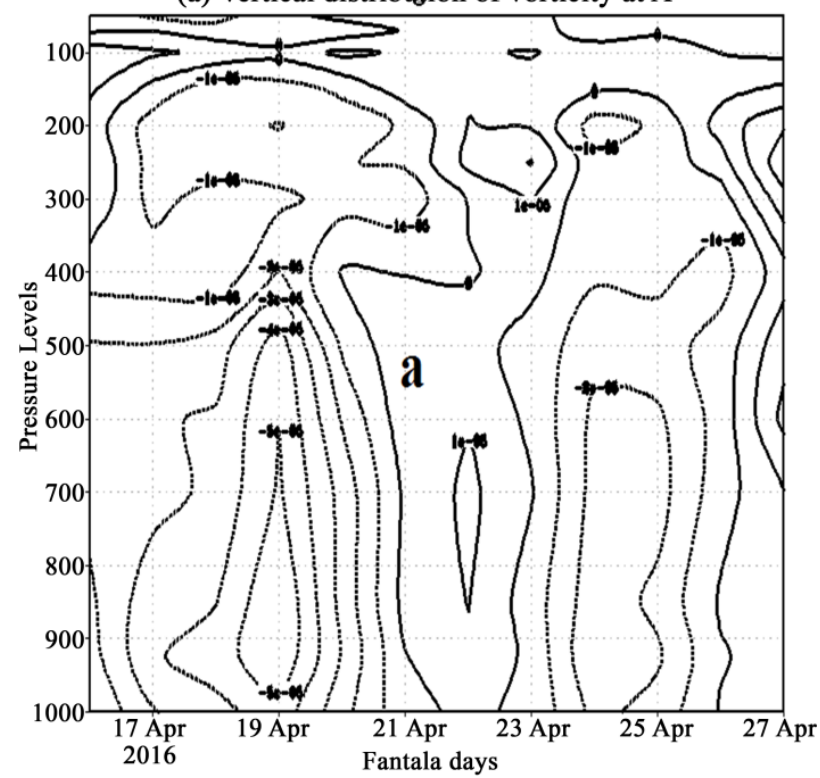

(c) distribution of $u$ winds at $B$

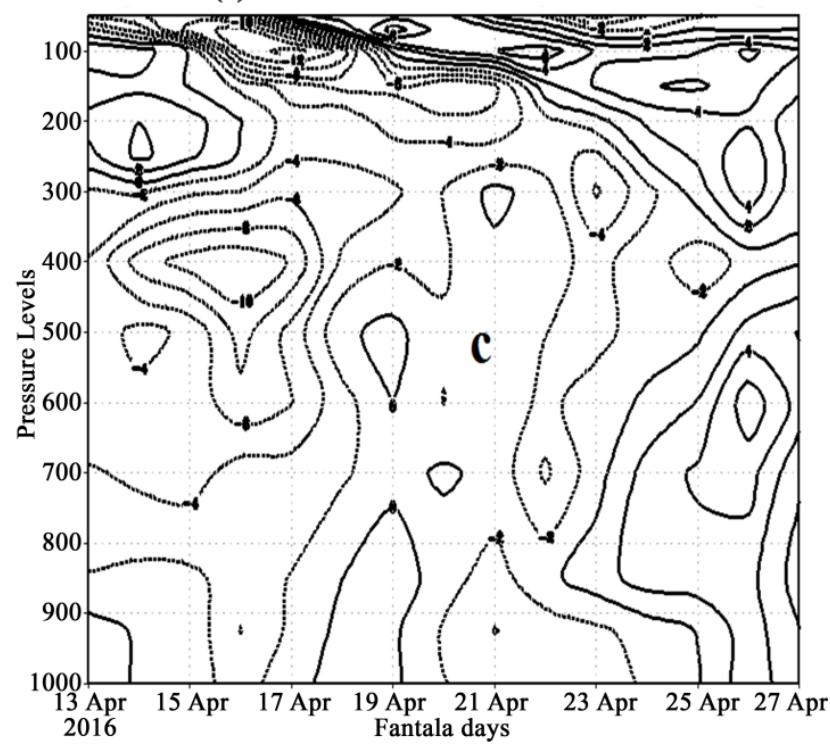

(b) vertical distribution of vorticity at B

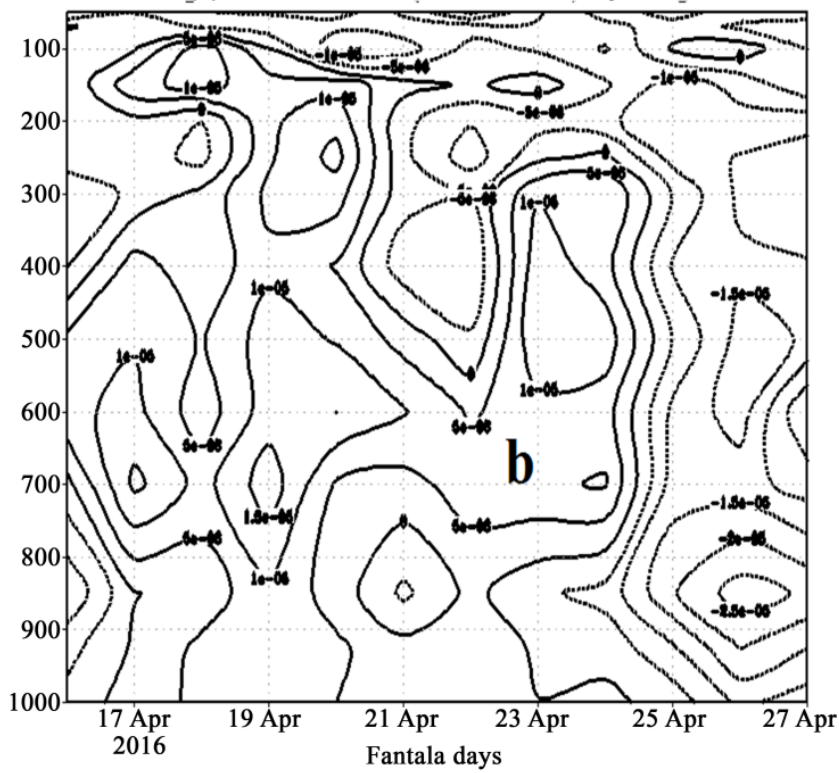

(d) distribution of $\mathrm{v}$ winds at $\mathrm{B}$

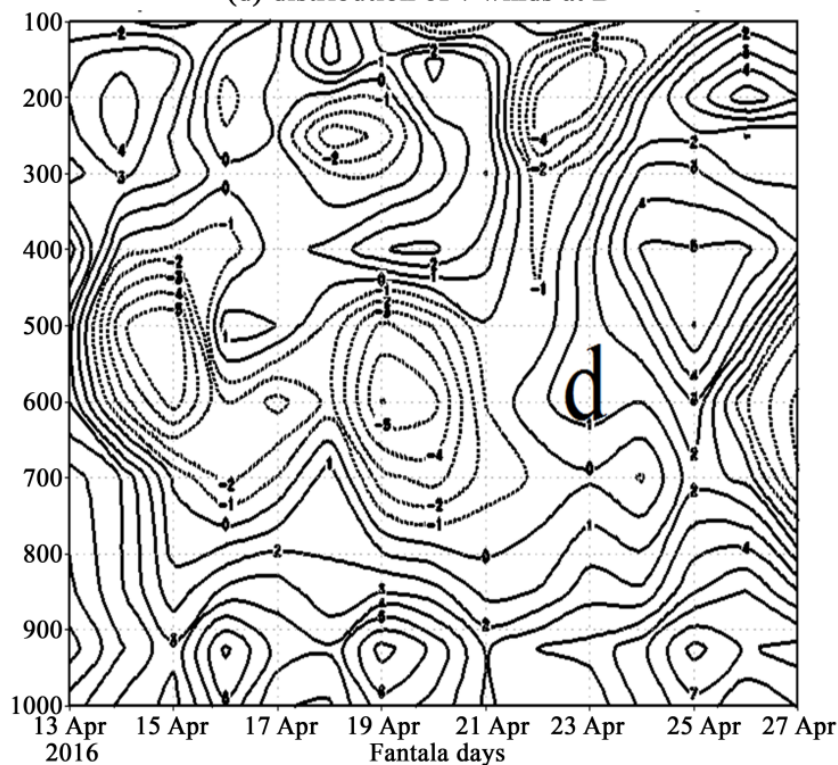

Figure 7. The Distribution of the vertical distribution of vorticty at A and B, and the vertical wind distribution at B during Fanlata days; where (a) and (b) vertical distribution of vorticity at A and B and (c) and (d) distribution of $u$ and v winds at B. Solid and dotted lines refer to the positive and negative values, respectively. Note that, for zonal winds $(\mathrm{u})$ the negative and positive values indicate the easterly and westerly flows, while for the meridional winds (v) the negative and positive values indicate the north and south winds, respectively.

winds or ocean currents, thus the results presented in Figure 7 (d) shows that during Fantala at point B the cyclone developed energy was from surface to 850 $\mathrm{mb}$ was being transferred northward by southerly winds which ranged from 0 - 8 $\mathrm{ms}^{-1}$ throughout the Fantala life, whereas from $850-200 \mathrm{mb}$ i.e. the middle of the atmosphere the TCs developed energy was being transferred southward by northerly winds which ranged from $0-6 \mathrm{~ms}^{-1}$. Besides, the results in Figure 7 (d) revealed that $13^{\text {th }}$ to $22^{\text {nd }}$ April, 2016 the atmosphere at point B was domi- 
nated by lower level southerly flow and upper level northerly flow while from $23^{\text {rd }}$ to $27^{\text {th }}$ the entire atmospheric column at point B was influence by northerly flow.

\subsection{The Rainfall Impacts of Fantala on Tanzanian Coastal Line}

The impact of Fantala on Zanzibar and the Tanzanian coastal line at large was analyzed using the real time satellite images (during TC Fantala), station observation rainfall records, and the MAM seasonal rainfall at different stations in Zanzibar. These stations include Karume airport, Pemba airport, Makunduchi, Kizimbani, Kilombero and Matangatuani (Figure 8). The results revealed that, the 16 days total rainfall caused/enhanced/contributed by Fantala (Figure 8(a) blue bars) ranged from $551 \mathrm{~mm}$ (at Kizimbani) to $256 \mathrm{~mm}$ (at Matangatuani), and were more concentrated at Unguja rainfall stations than in Pemba, indicating that the influence of low level $(850 \mathrm{mb})$ south easterly flow, 850 and $700 \mathrm{mb}$ moisture content $(\mathrm{Rh})$, and their zonal and meridional linear winds convergences had more effect on Uguja than in Pemba. Moreover, the results show that, the total rainfall of April, 2016 over most stations in Unguja was highly contributed by the influence of Fantala such that, the difference between the Fantala total rainfall (blue bars) and the total rainfall of April, 2016 (red bars)
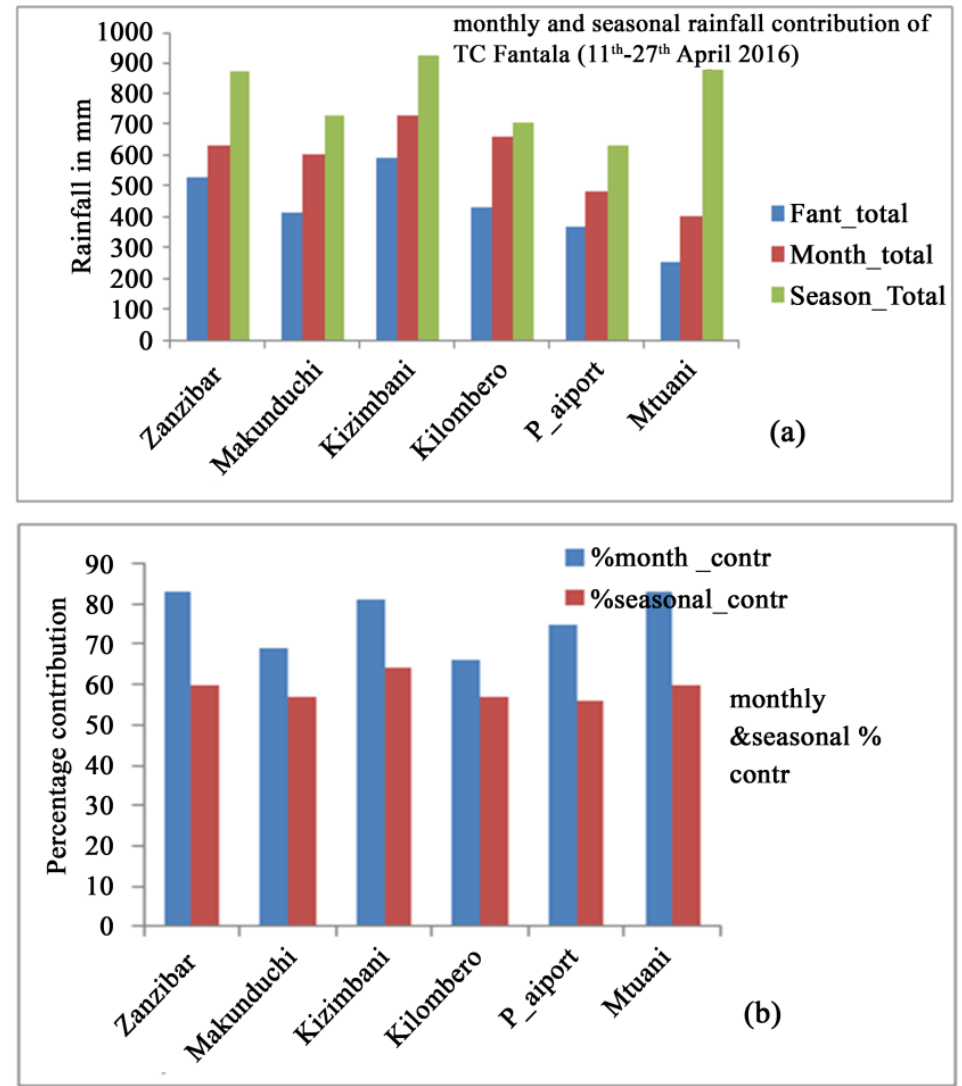

Figure 8. The monthly and seasonal rainfall contribution due to TC Fantala $\left(11^{\text {th }}-27^{\text {th }}\right.$ April, 2016) over coastal stations: (a) shows the monthly and seasonal contribution and (b) monthly and seasonal percentage contribution. 
was small in most stations, indicating that Fantala had significant rainfall contribution in Unguja. Besides, the results in Figure 8(a) show that, MAM, 2016 seasonal rainfall (Figure 8(a) green bars) was also highly influenced by the 16 days Fantala total rainfall (blue bars) as well as the April, 2016 total rainfall (red bars). Indeed, the results in Figure 8(a) revealed that the temporal distribution of MAM, 2016 seasonal rainfall was very poor, indicating that in most stations (except Matangatuani Pemba) the MAM, 2016 rainfall were characterized by great number of dry spells such that the MAM, 2016 total rainfall over most stations was very small.

The results of the percentage contribution of total Fantala rainfall to the total April, 2016 rainfall and to the MAM, 2016 seasonal rainfall, presented in Figure 8(b) show that, Fantala rainfall had highest percentage rainfall contribution ranged from 83\% (Zanzibar Airport) to 63\% (at Matangatuani Pemba), besides, in most stations the \% contribution for the April, 2016 rainfall (Figure 8(b) blue bars) was more than $60 \%$ indicating that, Fantala had significant rainfall impact to the April, 2016 rainfall. Moreover, the \% contribution of Fantala to MAM, 2016 seasonal rainfall (Figure 8(b) red bars) show that, the Fantala associated rainfall had highest contribution of more than 50\% to the MAM, 2016 seasonal rainfall in most stations in Zanzibar. This indicates that with the absence of Fantala the MAM, 2016 seasonal rainfall would have been too bad in most stations.

The results of the rainfall totals for the months of March, April, and May of the four consecutive MAM seasons (i.e. 2013 to 2016) for some stations in Zanzibar (Figure 9) revealed that, the April, 2016 rainfall was the highest monthly recorded rainfall throughout the four seasons over all investigated stations, besides the results in Figure 9 shows that, the spatial distribution of rainfall over all investigated stations and for all four seasons was quite good, but the temporal rainfall distribution was very poor in MAM, 2016 with large amount of rainfall records in April and very small amount in March and May. Additionally, the results in Figure 9 revealed that, the rainfall strengths for the 2013-2015 was higher at Makunduchi (Figure 9(b)) and Kilombero (Figure 9(c)) as compared to Zanzibar airport (Figure 9(a)), while all investigated stations had high inter seasonal rainfall variability from 2013-2016. For instance, for the month of May, Zanzibar airport had the high rainfall variability; Makunduchi had an increasing trend of rainfall, while Kilombero mimicked the patterns of Makunduchi. Similar trends were shown for the months of March and April (except for the April, 2016). As for the March rainfall, Kilombero portrayed a decreasing trend while, Zanzibar airport had an increasing trends.

\subsection{The Satellite and GFS Based Conditions during Fantala (11'th-27th April, 2016)}

This results of the investigated real time, observed and forecasted weather associated with the occurrence of Fantala indicated that, during Fantala days the real 

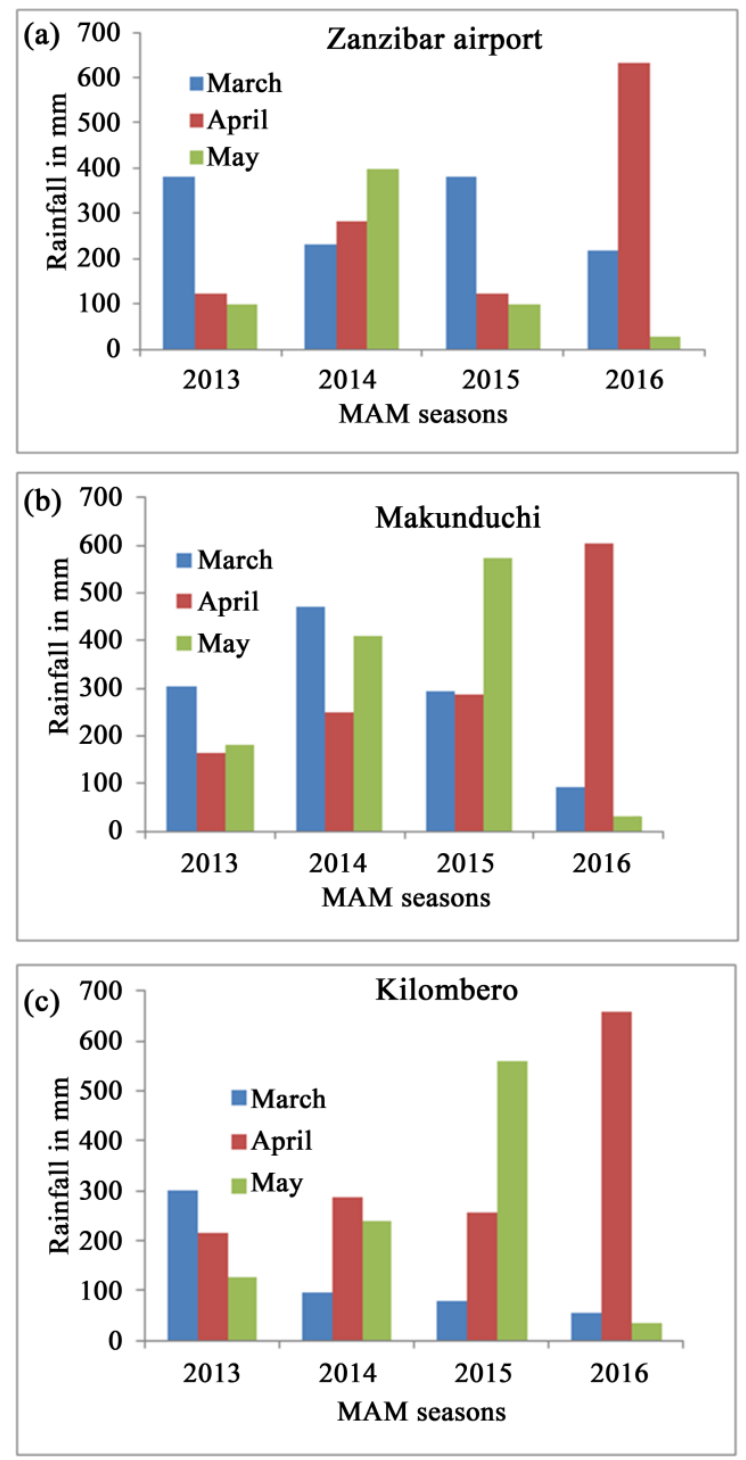

Figure 9. The MAM rainfall distribution over some rainfall stations in Zanzibar where (a) is for Zanzibar airport, (b) is for Makunduchi, and (c) is for Kilombero.

time satellite images shown in Figure 10 portrayed very severe conditions which were in agreement with the dynamics and thermodynamics of the Fantala presented in Figure 1 to Figure 5. Specifically Figure 10(a) shows a strong convective storm at 12:15Z (MSG infrared 108 of $1215 Z$ i.e. MSG METEOSAT 10) approaching the coast of Tanzania on $26^{\text {th }}$ April, 2016. This situation was agreed by the south easterly wind flow at $850 \mathrm{mb}$ presented in Figure 5(b) and Figure 5(c) as well as $850 \mathrm{mb}$ moisture distribution presented in Figure 2(a) and Figure 2(b) and Figure 3, respectively. The results presented in Figure 10(b) revealed the weather condition on $26^{\text {th }}$ April, 2016 during 15:00Z (three hours ahead of Figure 10(a)) using the infrared channel are quite similar to that of Figure 10(a) which shows how the coastal stations were affected by the influence of Fantala. The outcome of the Fantala condition shown in Figure 10(a) \& Figure 10(b) resulted observed rainfall records of $40 \mathrm{~mm}$ (Zanzibar Airport), $36.4 \mathrm{~mm}$ 

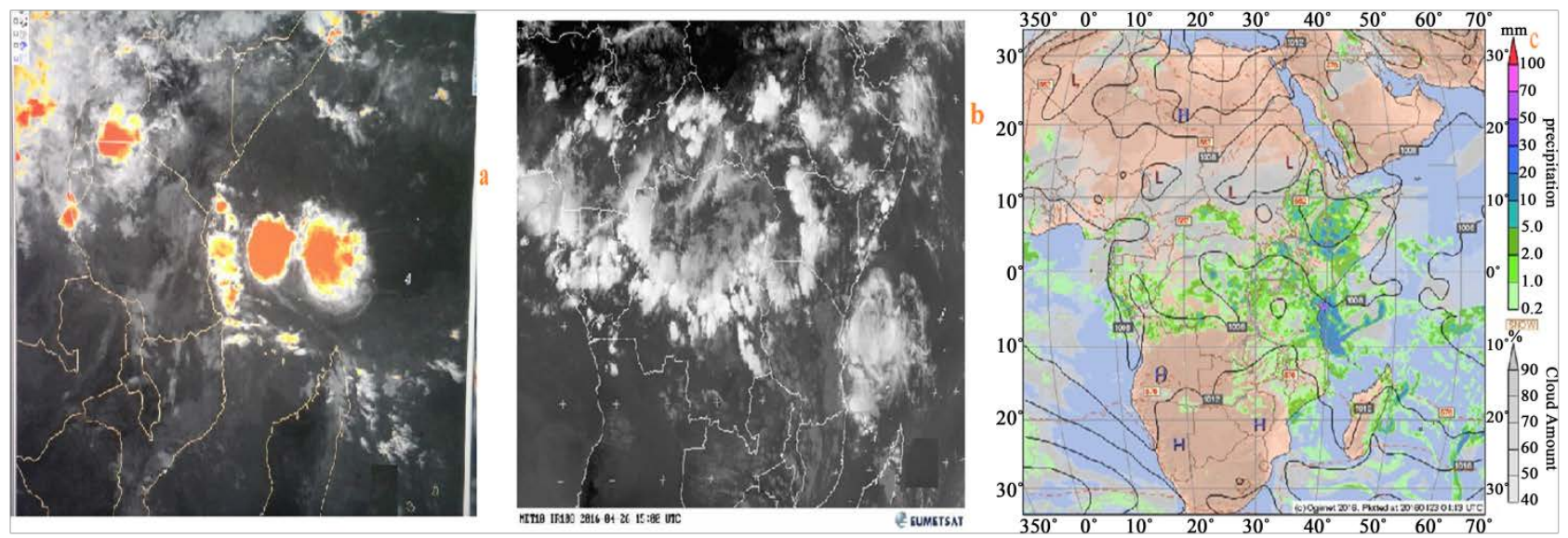

Figure 10. The real time satellites and modeled conditions of the Fantala; where (a) and (b) are the Infrared convective satellite channels showing the storms near the coast of Tanzania on $26^{\text {th }}$ April, 2016 and (c) is the OGIMET GFS prediction model showing the forecasted rainfall condition for $28^{\text {th }}$ April, 2016.

(Victoria garden), and $27.5 \mathrm{~mm}$ (Makunduchi), respectively. Figure 10 (c) shows the OGIMET GFS (www.ogimet.com) model forecasts indicating that, on Thursday $28^{\text {th }}$ April, 2016 between 0600 to $1200 \mathrm{Z}$ the coast of Tanzania will experience heavy rainfall of about $30-50 \mathrm{~mm}$, the outcome of this forecast revealed the total, observed rainfall on $28^{\text {th }}$ and $29^{\text {th }}$ April 2016 over most station in Zanzibar were $57.3 \mathrm{~mm}$ (Zanzibar airport), $100.4 \mathrm{~mm}$ (Makunduchi), $81.8 \mathrm{~mm}$ (Kilombero), $52.7 \mathrm{~mm}$ (Kizimbani), among others, these results indicate that the model forecast, that the Fantala rainfall impact will be significant over the coastal Tanzania was very correct.

\subsection{Socio-Economic Impacts Accompanied by the Presence of Fantala}

Apart from affecting the temporal and spatial distribution of the MAM, 2016 season the presence of TC Fantala $\left(11^{\text {th }}-27^{\text {th }}\right.$ April, 2016) had resulted in many socio-economic disruptions to the Tanzanian coastal line Zanzibar in particular. These impacts include the flooding which left more than 420 people homeless, and at least 3330 houses were destroyed, and a death toll of about 2 people was also reported (source: Commission for disaster management, in the Second Vice president's office of RoGZ). To accommodate the victims of the Fantala flooding, the disaster management department initiated temporary camps for flood victims. The camps run for approximately two weeks, where all house hold needs for the flood victims were supplemented by the Government. The costs of these camping incurred by the RoGZ were about USD 50,000. Moreover, the Government in Zanzibar through the ministry of education was forced to close the nursery and primary schools for about two weeks. Some of the impacted flooding areas due to Fantala are those presented in Figure 11, where some houses at Sebleni, Ziwamaboga, Kwabintiamaran and Kibondemzungu as well as the entrance areas of the Zanzibar airport were flooded. Other impact which their occurrence and incurred costs were not yet fully documented include, the 

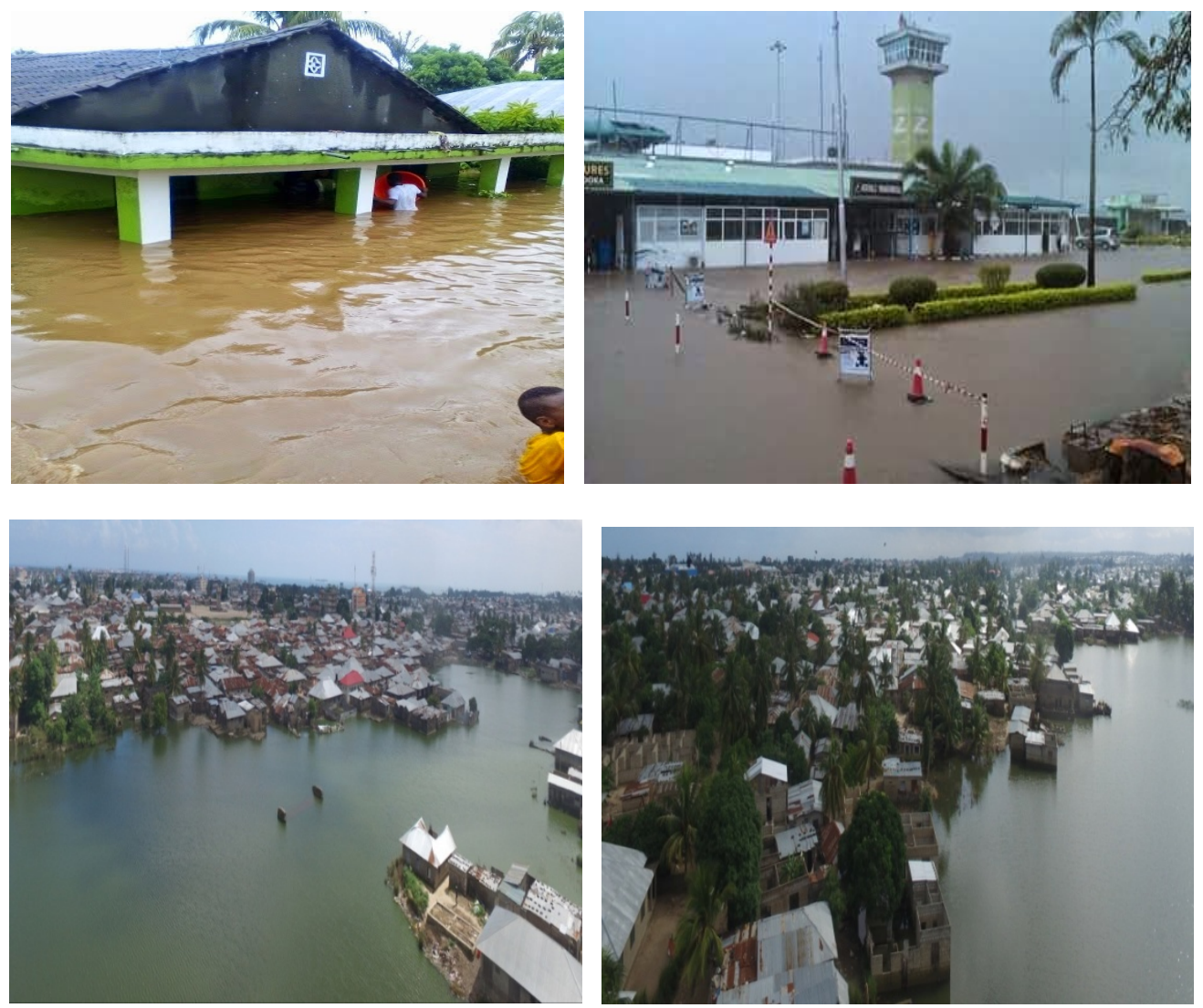

Figure 11. The flooding impacts associated with Fantala on $17^{\text {th }}$ April 2016: Top left panel flooding due to Fantala on some areas in Zanzibar; Top right panel, flooded Zanzibar airport entrance; bottom left panel flooding at Sebuleni areas and the bottom right panel, flooding at Ziwamaboga.

water related diseases (such as typhoid, cholera), crops, falling of trees, falling of power transmission lines, destruction of public houses such as dispensaries secondary schools, due to the impacts of Fantala. Apart from Zanzibar, TC Fantala highly affected most regions in Tanzania mainland. For instance, the outcomes of the TMA heavy rainfall warning issued in April, 2016 [31] have shown that in Kilimanjaro region, the Fantala rains caused flooding that covered roads and entered houses, trapping hundreds of residents and a recorded death toll of eight people. Also a death toll of five people was recorded in Morogoro due to flooding [32] [33] [34]. This flooding led to about 13,933 people being homeless after 315 houses being washed away. Besides, these flooding also washed away 12,073 ha of crop fields. This catastrophic event led the disaster management and rescue officials of the United Republic of Tanzania (URT) to purchase and distribute maize, beans, and cooking oil to affected residents [32] [33]. As for Kenya, Fantala influenced a four hours heavy rainfall record of at least $131 \mathrm{~mm}$, resulting in flooding in coastal portions of Kenya that destroyed several houses and about 10,000 ha (25,000 acres) of crop fields were flooded. Moreover, Kenyan Red Cross at Kwale County, has reported that many families suffered in the floods which caused widespread damage to property and several houses have been completely destroyed. Among the worst affected villages include Kiwegu, Bondeni, Mwarongo, Yogon and Matoroni 
(http://floodlist.com/africa/tropical-cyclone-fantala-triggers-heavy-rainfall-floodingcoastal-kenya).

\subsection{Discussions}

Tropical cyclone (TC) has been among the natural weather phenomenon which brings adverse impacts to both Tanzanian coastal lines and its hinterlands. Though the impacts of TCs to the coastal areas of EA depend on its position, strength and season [35] but most TCs become destructive to the Tanzania coast. Some of the TCs such as Gafilo ( $1^{\text {st }}$ to $18^{\text {th }}$ March, 2004), Bondo $\left(15^{\text {th }}-26^{\text {th }}\right.$ December, 2006), Felleng $\left(26^{\text {th }}\right.$ January $-3^{\text {rd }}$ February, 2013) and Fobane $\left(6^{\text {th }}\right.$ to $14^{\text {th }}$ February, 2014) had resulted in excessive rainfall and flooding in different parts of Tanzania such as Igunga and Magu [36]. Moreover, other TCs e.g. Felleng declined the weather of the northern coastal areas of Tanzania [6] [7] [8] [9]. Indeed, reference [6] has noted that the percentage rainfall contribution due to TCs during December to March (DJFM) over most stations in Tanzania ranged from 22.2\% in Mbeya and $16.1 \%$ in Dar es Salaam, whereas over the coastal region the highest and lowest contribution was $20.5 \%$ and $16.1 \%$ at Mtwara and Dar es Salaam, respectively. The analysis of the TC Fantala had resulted in great impacts on Tanzanian coastal line Zanzibar in particular and even at hinterlands (e.g. Morogoro and Kilimanjaro); these impacts ranged from socio-economic (loss of property) to loss of life. Moreover, the existence of Fantala had declined the temporal and spatial rainfall distribution of the MAM, 2016 rainfall season over most stations in Zanzibar Figures 8-10. Also the presented dynamics and thermodynamics of Fantala (shown in Figure 1 to Figure 7) had revealed that, both conditions for TCs genesis and intensification were met. For instance, the SSTs anomaly thresh hold of greater than $+2.3^{\circ} \mathrm{C}$ (Figure 1 (b)), vertical wind shear range of 5 to $10 \mathrm{~ms}^{-1}$ Figure 6(a) \& Figure 6(b), over the SWIO region during the existence of Fantala, the low level $(850 \mathrm{mb}) \mathrm{Rh}$ of at least $80 \%$ Figure 2(a) \& Figure 2(b) and (Figure 3), the easterly and westerly horizontal $\mathrm{u}$ and $\mathrm{v}$ wind changes with height during the existence of Fantala (Figure 7(c) and Figure 7(d) and the variation of vorticity with height Figure 7 (a) \& Figure 7 (b) which showed the tilting of the vortex with height, were among the conditions which supported the severe weather condition pertained during Fantala. These conditions were clearly shown by the real time satellite images Figure 10(a) \& Figure 10(b).

Since SWIO TCs season starts from November to May [5] and high TCs frequency and strong TCs occurs during December to March [5] and indeed the contribution of strong TCs to the seasonal rainfall forecast of October, November and December (OND) [37] [38] and MAM is not yet fully document or not well analyzed, there is need for the appropriate forecasting institutions to consider the detailed analysis of the contribution of TCs to OND and MAM seasonal rainfall predictions. Moreover, since TCs (Fantala and others in literature) have proved to lead to the catastrophic impacts on Tanzania coastal line, there is 
a need for the disaster management departments to have contingency plans for search and rescue. Also the need of having plans and algorithms to greatly quantify the total financial losses due to these extreme weather events is not avoided. Indeed, the forecasting institutions should have to develop their capability to accurately foreseen the TCs counts, strengths and their rainfall contribution to the EA region for combating the disaster prevention and reduction mechanisms.

\section{Conclusion}

The study has shown that both the dynamic and thermodynamic potentials of the tropical cyclone result in significant strength of the TC and hence increase the intensity of the impacts to the socio-economic livelihoods and even deaths. Moreover, the study has shown that TCs based on its position and track affect the rainfall pattern of the specific season (e.g. OND and MAM rainfall seasons). Hence since strong TCs including Fantala had great impacts on the Tanzania coasts, there is a need to extensively examine the TCs rainfall impacts and their contribution during our OND and MAM seasonal forecasts. Also extensive modeling studies on TCs frequency, tracks and landfalls are of significant importance. Indeed, coast benefit analysis programmes of the associated TCs losses to Tanzania and Zanzibar in particular should be launched.

\section{Acknowledgments}

The researcher would like to acknowledge the NCEP/NCAR reanalysis projects for their data assimilation and allowing the data to be on free access basis.TMA administration and staff and $\mathrm{R}_{\mathrm{O}} \mathrm{GZ}$ through the commission of disaster management should be acknowledged for provision of data on free of charge basis whenever requested. Indeed, I would like to thank the TMA forecasting desk at Zanzibar office for archiving the models products and satellite real time satellite images used in this study.

\section{Conflicts of Interest}

The authors declare no conflicts of interest regarding the publication of this paper.

\section{References}

[1] Michener, W.K. and Houhoulis, P.F. (1997) Detection of Vegetation Changes Associated with Extensive Flooding in a Forested Ecosystem. Photogrammetric Engineering and Remote Sensing, 63, 173-181.

[2] Rodgers, J.C., Cooke, W.H. and Murrah, A.W. (2009) The Impact of Hurricane Katrina on the Coastal Vegetation of the Weeks Bay Reserve, Alabama from NDVI Data. Estuaries and Coasts, 32, 496-507. https://doi.org/10.1007/s12237-009-9138-Z

[3] Chand, S.S. and Walsh, K.J.E. (2009) Tropical Cyclone Activity in the Fiji Region: Spatial Patterns and Relationship to Large-Scale Circulation. Journal of Climate, 22, 3877-3893. https://doi.org/10.1175/2009JCLI2880.1

[4] Chang-Seng, D.S. and Jury, M.R. (2010) Tropical Cyclones in the South Western Indian Ocean. Part I: Inter-Annual Variability and Statistical Prediction. Meteorology 
and Atmospheric Physics, 106, 149-162. https://doi.org/10.1007/s00703-009-0055-2

[5] Mavume, A.F., Rydberg, L., Mathieu, R. and Lutjeharms, J.R.E. (2006) Climatology and Landfall of Tropical Cyclones in the South West Indian Ocean. Western Indian Ocean Journal Marine Sciences, 8, 15-36. https://doi.org/10.4314/wiojms.v8i1.56672

[6] Kai, K.H. (2018) Impacts of Southwestern Indian Ocean Tropical Cyclones and Storms on the Rainfall Pattern and Vegetation Productivity over Tanzania. Thesis, the Institute of Marine Sciences of the University of Dar Es Salaam, Dar Es Salaam, $297 \mathrm{p}$

[7] da Conceição Jr., P. (2004) Mozambique: Assessment for Maputo, Mozambique. A Summary UN-HABITAT Nairobi Kenya.

[8] Arnold, A. (2012) An Overview and Brief History of Southern Hemisphere Tropical Cyclones. http://www.csa.com/discoveryguides/discoveryguides-main.php

[9] Vitart, F., Anderson, D. and Stockdal, T. (2003) Seasonal Forecasting of Tropical Cyclone Landfall over Mozambique. Journal of Climate, 16, 3932-3945. https://doi.org/10.1175/1520-0442(2003)016\%3C3932:SFOTCL\%3E2.0.CO;2

[10] Mahongo, S.B., Francis, J. and Osima, S.E. (2011) Wind Patterns of Coastal Tanzania; Their Variability and Trends. Western Indian Ocean Journal of Marine Science, 10, 107-120.

[11] Blumel, S.M. (1984) The Tanzanian Hurricane of 14-16 April, 1952. National Weather Digest, 9, 34-35.

[12] Francis, J., Mahongo, S., Semesi, A., Muhando, C., Mgaya, Y., Daffa, J. and Ngoile, M. (2001) Eastern Africa Atlas of Coastal Resources: Tanzania. United Nations Environment Programme, Nairobi, $111 \mathrm{p}$.

[13] Reynolds, R.W., Smith, T.M., Liu, C.Y., Chelton, D.B., Casey, K.S. and Schlax, M.G. (2007) Daily High-Resolution-Blended Analyses for Sea Surface Temperature. Journal of Climate, 20, 5473-5496. https://doi.org/10.1175/2007JCLI1824.1

[14] Frank, W.M. and Ritchie, E.A. (2001) Effects of Vertical Winds Shear on the Intensity and Structure of Numerically Simulated Hurricanes. Monthly Weather Review, 129, 2249-2269. https://doi.org/10.1175/1520-0493(2001)129\%3C2249:EOVWSO\%3E2.0.CO;2

[15] Frank, W.M. and Ritchie, E.A. (1999) Effects of Environmental Flow upon Tropical Cyclone Structure. Monthly Weather Review, 127, 2044-2061. https://doi.org/10.1175/1520-0493(1999)127\%3C2044:EOEFUT\%3E2.0.CO;2

[16] Ritchie, E.A. and Frank, W.M. (2007) Interactions between Simulated Tropical Cyclones and an Environment with a Variable Coriolis Parameter. Monthly Weather Review, 135, 1889-1905. https://doi.org/10.1175/MWR3359.1

[17] Rogers, R., Reasor, P. and Lorsolo, S. (2013) Airborne Doppler Observations of the Inner-Core Structural Differences between Intensifying and Steady-State Tropical Cyclones. Monthly Weather Review, 141, 2970-2991. https://doi.org/10.1175/MWR-D-12-00357.1

[18] Chand, S.S., Walsh, K.J.E. and Chan, J.C.L. (2010) A Bayesian Regression Approach to Sesonal Prediction of Tropical Cyclones Affecting the Fiji Region. Journal of Climate, 23, 3425-3445. https://doi.org/10.1175/2010JCLI3521.1

[19] Kupferman, R. (2001) A Central-Difference Scheme for a Pure Stream Function Formulation of Incompressible Viscous Flow. SIAM Journal on Scientific Computing, 23, 1-18. http://www.siam.org/journals/sisc/23-1/37339.html https://doi.org/10.1137/S1064827500373395

[20] Kopal, A. and Prasanjit, D. (2016) Towards Dependence of Tropical Cyclone Inten- 
sity on Sea Surface Temperature and Its Response in a Warming World. Journal of Climate, 4, 30. https://doi.org/10.3390/cli4020030 http://www.mdpi.com/journal/climate

[21] Crespo, L.R., Keenlyside, N. and Koseki, S. (2018) The Role of Sea Surface Temperature in the Atmospheric Seasonal Cycle of the Equatorial Atlantic. Climate Dynamics, 52, 5927-5946. https://doi.org/10.1007/s00382-018-4489-4

[22] Rudi, J., Van der Ent, R.J. and Savenije, H.H.G. (2013) Oceanic Sources of Continental Precipitation and the Correlation with Sea Surface Temperature. Water Resources Research, 49, 3993-4004. https://doi.org/10.1002/wrcr.20296

[23] Gray, C.W. (1979) Hurricanes: Their Formation, Structure and Likely Role in the Tropical Circulation. In: Shaw, D.B., Ed., Meteorology over the Tropical Ocean, Royal Meteorological Society, Bracknell, 155-218.

[24] Courtney, J. and Knaff, J.A. (2009) Adapting the Knaff and Zehr Wind-Pressure Relationship for Operational Use in Tropical Cyclone Warning Centers. Australian Meteorology and Oceanographic Journal, 58, 167-179. https://doi.org/10.22499/2.5803.002

[25] Gray, W.M., Landsea, C.W., Mielke Jr., P.W. and Berry, K.J. (1993) Predicting Atlantic Basin Seasonal Tropical Storm Activity by 1 August. Weather and Forecasting, 8, 73-86. https://doi.org/10.1175/1520-0434(1993)008\%3C0073:PABSTC\%3E2.0.CO;2

[26] Gray, W.M., Landsea, C.W., Mielke Jr., P.W. and Berry, K.J. (1994) Predicting Atlantic Basin Seasonal Tropical Storm Activity by 1 June. Weather and Forecasting, 9, 103-115. https://doi.org/10.1175/1520-0434(1994)009\%3C0103:PABSTC\%3E2.0.CO;2

[27] Zehr, R.M. (1992) Tropical Cyclogenesis in the Western North Pacific. NOAA Technical Report NESDIS6, National Oceanic and Atmospheric Administration, Washington DC, $181 \mathrm{p}$.

[28] Gallina, G.M. and Velden, C.S. (2002) Environmental Vertical Wind Shear and Tropical Cyclone Intensity Change Utilizing Satellite Derived Wind Information. 25th Conference on Hurricanes and Tropical Meteorology, San Diego, 28-29 April 2002, 172-173.

[29] Palmer, C.K. and Barnes, G.M. (2002) The Effects of Vertical Wind Shear as Diagnosed by the NCEP/NCAR Reanalysis Data on Northeast Pacific Hurricane Intensity. 25th Conference on Hurricanes and Tropical Meteorology, San Diego, 28-29 April 2002, 122-123.

[30] Paterson, L.A., Hanstrum, B.N., Davidson, N.E. and Weber, H.C. (2005) Influence of Environmental Vertical Wind Shear on the Intensity of Hurricane-Strength Tropical Cyclones in the Australian Region. Monthly Weather Review, 133, 3644-3660. https://doi.org/10.1175/MWR3041.1

[31] Tanzania Meteorological Agency (2016) Heavy Rains Warning. African News, 23 April, 2016.

[32] Philippine News Agency (2016) Floods Kill Seven in Norhern Tanzania.

[33] Philippine News Agency (2016) Five Killed, over 13,000 Left Homeless by Floods in Eastern Tanzania.

[34] Météo-France (2016) Very Intense Tropical Cyclone 8 (Fantala) Warning 27 (Report) Archived from the Original on 18 April 2016.

[35] Mutemi, J.N. (2003) Climate Anomalies over Eastern Africa Associated with Various ENSO Evolution Phases. PhD Thesis, University of Nairobi, Kenya. 
[36] Tanzania Meteorological Agency (2006) Decadal Weather Review. No. 12 2006/07 Cropping Season; 21-31 December, 2006.

http://www.wamis.org/countries/tanzania/tanzdwr2006123.pdf

[37] Chang'a, L.B., Kijazi, A.L., Mafuru, K.B., Kondowe, A.L., Osima, S.E., Mtongori, H.I., Ng'ongolo, H.K., Juma, O.H. and Michael, E. (2020). Assessment of the Evolution and Socio-Economic Impacts of Extreme Rainfall Events in October 2019 over the East Africa. Atmospheric and Climate Sciences, 10, 319-338.

https://doi.org/10.4236/acs.2020.103018

[38] Kai, K.H., Kijazi, A.L. and Osima, S.E. (2020). An Assessment of the Seasonal Rainfall and Its Scietal Implications in Zanzibar Islands during the Season of October to December, 2019. Atmospheric and Climate Sciences, 10, 509-529.

https://doi.org/10.4236/acs.2020.104026 